\title{
PROJETO POLÍTICO-PEDAGÓGICO: uma possibilidade de gestão democrática
}

\author{
Daianny Madalena Costa 102
}

\section{RESUMO}

Neste artigo, partimos da promulgação da Constituição Federal (1988), enquanto um marco a favor da democracia, a qual estabeleceu a educação como direito social (art $6^{\circ}$ ), que visa o pleno desenvolvimento humano (art. 205) e que tem a gestão democrática como princípio (art. 206, VI). Dela decorreu o conjunto de legislações posteriormente. Porém, por mais que uma lei aponte para um fim, é inegável a participação da sociedade para que efetivamente se consolide. Assim, por meio de uma metodologia dialógica, entre ação-reflexão-ação, analisaremos a construção dos projetos políticos-pedagógicos (PPPs) enquanto uma possibilidade viável de gestão democrática, realizada numa rede municipal de educação, de uma cidade da região Metropolitana do Vale do Paraíba, no estado de São Paulo. Bobbio (1986) afirma que "para o regime democrático, o estar em transformação é seu Estado natural: a democracia é dinâmica, o despotismo é estático e sempre igual a si mesmo" (p. 9). Desse modo, buscar princípios democráticos, significa compreendê-los em transformação e permanente negação aos autoritarismos e despotismos que fazem parte dos jogos do poder. Consideramos, portanto, que os PPPs podem ser a proposta enunciada para um planejamento participativo e democrático e, ao mesmo tempo, seu guardião. Ou seja, da mesma forma que o convite realizado para sua preparação seja por meio de uma construção coletiva, democrática e participativa, a gestão democrática será pautada enquanto "um capítulo", construída no cerne do documento, que remeta a uma constante apropriação, amadurecimento e sustentação da vida escolar como princípio democrático.

Palavras-chave: Projeto Político-Pedagógico. Democracia. Participação.

\section{POLITICAL-EDUCATIONAL PROJECT: a possibility of a democratic management}

\begin{abstract}
In this article, we start from the promulgation of the Federal Constitution (1988), as a mark for democracy, which established education as a social right (article 6), which aims at the full human development (article 205) and which has the democratic management as principle (article 206, VI). It was based on this principle that all constitutional legislation was set posteriorly. However, for more than a law point to an end, it is undeniable the participation of society in order to effectively consolidates it.

102 Doutora em Educação pela Universidade do Vale do Rio dos Sinos. Docente do Mestrado Profissional em Gestão Educacional, da Universidade do Vale do Rio dos Sinos, campus Porto Alegre. E-mail: daiannycosta@hotmail.com
\end{abstract}

Revista Exitus, Santarém/PA, Vol. 7, № 1, p. 200-221, Jan/Abr 2017. 
Thus, through a dialogic methodology of action-reflection-action, we will examine the construction of political-pedagogical projects (PPPs) as a viable possibility of democratic management, held in a municipal education in a city of the metropolitan region of Vale do Paraíba, in the state of Sao Paulo. Bobbio (1986) states that "for the democratic regime, the 'being' in the transformation is its natural state: democracy is dynamic, despotism is static and always equal to itself" (p. 9). Thus, to seek democratic principles means to understand them in transformation and permanent denial of authoritarianism and despotism that are part of the power games. Therefore, we consider that the PPPs can be the proposal set out to a participatory and democratic planning and they are their guardian at the same time. In other words, the same invitation that was made to their preparation through a collective, democratic and participatory construction, the democratic management will be guided as a "chapter", built in the core of the document that refers to a constant appropriation, maturing and supporting of school life as a democratic principle.

Keywords: Political-Pedagogical Project. Democracy. Participation.

\section{INTRODUÇÃO}

Refletir acerca dos projetos político-pedagógicos enquanto uma possibilidade de gestão democrática requer algumas perguntas, alguns entendimentos a priori. Enfatizamos, por isso, os aspectos legal e histórico, registrados no Brasil a partir da Constituição de 1988.

Do acúmulo de desgastes vividos pelo regime militar, havia também as disputas dentro das próprias Forças Armadas e o desagrado das elites brasileiras que não viam os benefícios do período conhecido como "milagre econômico", além da consequente crítica à estatização da economia (VIOLA, 2008) que já via fortes contradições com o período da neoliberalização que se concretizava nos governos Thatcher (Inglaterra) e Reagan (Estados Unidos).

Gradativamente eram tantas as manifestações nas ruas, tantos os descontentamentos, que os comandantes da ditadura militar, especialmente o governo Geisel, se viram compelidos a criar um conjunto de medidas que viabilizassem uma transição para a democracia. Foi assim que o período que dava fim aos governos militares teve uma eleição indireta para presidente da república, em 1985, que elegeu um governo civil e que propunha uma assembleia constituinte, a qual cumpriria a difícil tarefa de 
reconstruir a constituição do país, num momento em que se reivindicava o democrático.

Em 1988, os deputados constituintes promulgaram a Constituição Cidadã, propondo também uma educação para este fim. A Carta Magna (1988), como também é conhecida, estabelecia a educação enquanto direito social (art $6^{\circ}$ ), que visa o pleno desenvolvimento humano (art. 205) e terá a gestão democrática como princípio (art. 206, VI).

Nesse sentido, a Lei de Diretrizes e Bases da Educação Nacional, Lei Darcy Ribeiro, sancionada (1996), reforçou a ideia da gestão democrática como princípio da educação brasileira (Lei 9394/96, art. 3º, VIII). Mais adiante, no art. 14, dessa mesma lei, claro estão os princípios da gestão democrática: "I - participação dos profissionais da educação na elaboração do projeto pedagógico da escola; II - participação das comunidades escolar e local em conselhos escolares ou equivalentes" [grifo nosso].

Também o Plano Nacional de Educação, aprovado em 2014, dispõe como diretriz a promoção da gestão democrática (art. $2^{\circ}, \mathrm{VI}$ ) e estabelece o seguinte:

Art. 9o Os Estados, o Distrito Federal e os Municípios deverão aprovar leis específicas para os seus sistemas de ensino, disciplinando a gestão democrática da educação pública nos respectivos âmbitos de atuação, no prazo de 2 (dois) anos contado da publicação desta Lei, adequando, quando for o caso, a legislação local já adotada com essa finalidade (Lei No 13.005, DE 25 DE JUNHO DE 2014).

Para analisar a produção política e legal, usaremos "O ciclo de políticas", proposto por Stephen Ball (apud MAINARDES, 2006), o qual nos oportuniza um referencial analítico útil e permite uma compreensão crítica e contextualizada de programas e políticas educacionais, porque, em sendo um construto, passa por um conjunto de práticas e sofre uma releitura permanentemente.

Cabe, para este trabalho, enfatizarmos dois, dos quatro contextos apresentados por Ball (apud MAINARDES, 2006): o contexto da produção e o 
contexto da prática. No contexto da produção encontramos a geração do texto político, sempre resultado de disputas e acordos, pois os grupos que atuam dentro dos diferentes lugares da produção desses textos competem para controlar as representações da política. No contexto da prática, reconhecemos que os autores dos textos políticos não podem controlar o significado dos seus escritos. Aqui acontece a efetiva assunção do papel ativo da compreensão e recontextualização dos textos, pois o fato de ter uma norma escrita, por exemplo, que vai numa direção, não significa que sua interpretação será realizada tal qual evidenciou o interesse de quem o produziu.

Nesse sentido, a lei, enquanto um aspecto básico na promoção de uma política educacional, aponta para que a escola brasileira se faça por meio de uma gestão democrática, mas isso por si só não a concretizará. Não basta estar previsto na lei para que a democracia, ou qualquer outra demanda aconteça. Por isso mesmo, pretendemos aqui, refletir sobre as condições viáveis de sendo um princípio legal, a gestão democrática, seja um elemento do fazer diários nas instituições escolares, porque o compromisso com a produção de uma escola que leve a promoção da cidadania contribui para uma sociedade mais democrática e de direitos.

Assim, defendemos que os projetos políticos-pedagógicos, enquanto documentos a serem construídos nas escolas, sejam ao mesmo tempo - a proposição de um planejamento participativo e democrático e seu guardião. Ou seja, ao mesmo tempo que sua construção se dará de maneira participativa e democrática, a gestão democrática será pautada enquanto "um capítulo" de constante apropriação, amadurecimento e sustentação da vida escolar.

\section{REFLEXÕES ACERCA DA DEMOCRACIA}

A afirmação realizada por Hobsbawn (2007) de que o século XX foi o mais mortífero de toda a história documentada, remete-nos ao sentido de 
produzirmos algumas considerações sobre as formas autoritárias e desrespeitosas que tramam nossa convivência. Frente a isso, declaramos a ideia de que os progressos tecnológicos que surpreenderam a capacidade dos limites humanos, não consolidaram a melhoria de vida de boa parte dos habitantes do planeta e ao contrário, tais avanços serviram mais para potencializar a indústria bélica do que para gerar paz.

Infelizmente, o século XXI iniciou tão violento quanto terminou o passado e mais trágico ainda é saber que não há nenhuma organização mundial com autoridade suficiente para controlar ou resolver as disputas armadas, e pelo contrário são os Estados que conferem poder a elas (HOBSBAWN, 2007).

Dito isso, partimos da premissa de que os anseios a favor da democracia não fazem descansar os desejos de que é admissível um mundo onde haja igualdade e justiça para todos. Muito embora possamos constatar que estamos um tanto longe desse ideal, a percepção de que seja possível sua construção, faz com que nos dediquemos a buscar caminhos, reflexões e fazeres para que sobrevenha.

Nesse sentido, o que pretendemos aqui é provocar uma discussão sobre o tema e mais adiante aproximá-lo da gestão escolar. Isso porque, acreditamos que o fazer democrático não se esgota somente na normatização legal, mas necessita da particapação das pessoas envolvidas para discutirem e chegarem aos modos de combete à injustiça, à plutocracia, aos despotismos, às desigualdades.

Sendo assim, perguntamo-nos sobre as possibilidades de reversão desse estado de coisas e encontramos na democracia, um elemento fundante para esse propósito, afinal, a democracia não combina com injustiças e desigualdades (BORON, 2002).

Nessa intenção, partiremos a tecer um conjunto de ideias acerca do que vem a ser a democracia.

Bobbio (1986) afirma que "para o regime democrático, o estar em transformação é seu Estado natural: a democracia é dinâmica, o 
despotismo é estático e sempre igual a si mesmo" (p. 9). Desse modo, podemos dizer que a democracia está em construção e, é por isso, inacabada. Por conseguinte, ao mesmo tempo de que é pauta de disputa entre os diversos segmentos da sociedade, é resultado das diferenças existentes. Buscar por princípios democráticos, portanto, significa compreendê-los em transformação e permanente negação aos autoritarismos e despotismos que fazem parte dos jogos do poder.

Talvez, a primeira ideia que nos ocorre a respeito da democracia, seja o direito ao voto. Nos estudos de Benevides (1996) destacamos sua contribuição a respeito da definição sobre esta forma de organização. A participação direta dos cidadãos em eleições, que confere aos seus representantes eleitos, o poder de decisão de grande parte dos assuntos da vida em sociedade, é denominada pela autora de democracia semidireta, ou seja, quando há um equilíbrio entre a soberania popular direta e sua representação.

Sobre isto, Bobbio (1996) sugere o seguinte: o incremento significativo do número de eleitores, - que se deu a partir do fim da sua vinculação à renda, da conquista do direito das mulheres, da redução da idade mínima, bem como do contemporâneo direito dos analfabetos - contribuíram para um importante avanço para a democracia, no que se refere ao direito de votar. Porém não caracteriza, por si só, um regime democrático. A expansão da democracia, para Bobbio (1986) está em exercer este direito em vários âmbitos do poder, é isto que de fato a caracteriza, o estar em movimento de expansão e conquistas.

Complementando este ponto de vista, que vislumbra a possibilidade de ampliação da democracia, trazemos a análise realizada por Gadotti (2012), a qual propõe que para haver democracia é necessário que a sociedade seja de direitos, portanto, cidadã. A esse aspecto, podemos destacar o incremento da participação por meio dos referendos, plebiscitos, emendas populares, orçamentos participativos, conselhos - nas esferas dos executivos e dos legislativos, alargando os direitos. Nesse mesmo sentido, 
Green (2009) concebe a cidadania ativa, como uma importante conquista de direitos, vinculando os indivíduos ao Estado, no sentido de reduzir as desigualdades sociais. Declara que por meio da participação, cidadãos se veem realizando ações coletivas ao se "fazerem ouvir", ampliando seus direitos e melhorando com isto sua condição de vida.

Também Touraine (1996) contribui para a reflexão em torno da democracia. Iniciando a partir da análise de que não pode ficar separada da ideia de direitos - de todos. Trata-se de aprendermos a vivermos juntos, tolerando as diferenças. Construir um mundo que sejamos cada vez mais abertos vivenciando a maior diversidade possivel. Daí que, a democracia prescinda de igualdade política, escolha, pluralidade, cidadania, envolvimento com a vida coletiva e a representatividade, enquanto reconhecimento dos direitos fundamentais.

No sentido de ampliarmos a discussão para a direção dos direitos, temos a contribuição de Boron (2009), que defende a tese de que a democracia para se efetivar, necessita responder favoravelmente ao acréscimo da igualdade social e econômica. Poderíamos imaginar a necessidade de ampliação das instituições democráticas que incorporem a participação popular, enquanto direito, e um Estado que possa promover tais condições. Para esse autor há ainda a dificuldade quanto à justiça, tão necessária à democracia e tão indiferente a uma sociedade que supervaloriza o consumo, o mercado.

Assim, podemos afirmar que o processo democrático está em constante construção/tensão enquanto possibilidade de concretizar o bem comum; e favorecer e fortalecer os direitos fundamentais à cidadania.

Isto posto, podemos crer que, quando nosso país viveu a reabertura democrática, após o silenciamento incorporado à nação nos duros anos da ditadura militar, a sociedade civil clamava por democracia. O que ocorreu daí foi um conjunto de ações e envolvimentos políticos que desembocaram em marcos legais e obviamente uma luta constante para sua garantia. 
Diante de tudo isso, acreditamos que o Brasil necessite uma escola que se reflita na relação estreita que tem de si mesma e na construção do país. Afinal, não podemos pensar na organização de uma democracia, sem construirmos e evidenciarmos o quanto a instituição escolar tem a ver com tamanho desafio. Obviamente, se um país se quer efetivar como um estado democrático de direito, como quer o Brasil, porque assim se nomeia constitucionalmente, a escola tem muito a cooperar para este fim.

O princípio de que cabe a escola brasileira ser gestada de forma democrática, por meio da participação de docentes, comunidade escolar está posto. A partir daí a discussão orbita em torno do como se construirá para tal finalidade. Afinal, não podemos negar o modelo vivido pela sociedade brasileira, a qual se caracterizou ao longo de vários períodos como um extremo centralismo nas figuras daqueles que dirigiam as diversas instituições que compunham o estado brasileiro e essa maneira de reger uma instituição ainda é muito presente no arcabouço administrativo.

Na escola, isso se situava na centralização constatada na figura do diretor (PARO, 2000). Então, como produzir na escola um outro tipo de liderança? Capaz de não abrir mão de seu mando, para alargar o poder e ampliar a discussão de qual escola, para que e para quem serve? Como escutar e compreender o que querem os atores que fazem parte de seu cotidiano? Quais seriam os instrumentos mais favoráveis para que esse poder fosse dilatado de fato?

Parece evidente que a escola como um todo, seus segmentos - pais, alunos, professores, funcionários, equipes gestoras - deveriam se por discutila. Evidenciar seus problemas e buscar soluções coletivas para eles.

Mas claro também que muitas vezes a própria sociedade não está convencida de que precisa se envolver. Então, parece necessário ser criado um conjunto de ações para que esta sociedade aprenda que é do seu envolvimento que as mudanças necessárias a seu favor aconteçam. E, para que isso sobrevenha, será imperativo que se comprometa com sua cidadania e lute por seus direitos, promovendo assim, a democracia. 
Nesse sentido, julgamos que a proposta de construção de um projeto político-pedagógico sirva para a finalidade de dilatar os processos democráticos. A escola estará ajudando o país a se fazer democrático, pois se é por intermédio da participação efetiva que contribuiremos e construiremos um Estado democrático, porque temos o dever de impulsionálo para este devir, a instituição educacional não poderá se furtar de seu grandioso papel de colaboradora. Isso significa que não se buscará democrática, porque assim a lei a impôs, mas porque se quer cidadã.

\begin{abstract}
A escola estatal só será verdadeiramente pública no momento em que a população escolarizável tiver acesso geral e indiferenciado a uma boa educação escolar. E isso só se garante pelo controle democrático da escola (...). Há, pois a necessidade permanente de se exercer pressão sobre o Estado, para que ele disponha a cumprir este dever. É neste contexto que ganha maior importância a participação da comunidade na escola, no sentido, anteriormente mencionado, de partilha do poder por parte daqueles que se supõe serem os mais diretamente interessados na qualidade do ensino (PARO, 2000, p. 17).
\end{abstract}

Nesta argumentação, portanto, apontamos para a existência de um Estado efetivamente democrático, quando estiver balizado pela participação popular. Para isto, será necessário que a sociedade civil também se respalde por modelos democráticos, ou seja, só participará se compreender que a democracia é fundamental para qualificarmos a nossa própria vida em comunidade.

É possível pensarmos que a escola que se quer enquanto possibilidade de ajudar a alavancar a transformação social, por meio da democracia, terá como compromisso a sua própria democratização como processo educativo, promovendo uma pedagogia que impulsione sua comunidade escolar para a participação e controle da esfera pública.

Dito isso, estamos a considerar uma democracia pretensamente realizada por meio da participação e por isso, democracia e participação compõem o mesmo tecido. São fios que se tramam, pois se uma das prerrogativas da democracia é a extensão do poder das pessoas, no sentido de exercerem sua cidadania, noutra esfera, isto só acontecerá se houver 
também uma presente participação da comunidade em todos os setores dos quais necessitam.

\section{PROJETO POLÍTICO-PEDAGÓGICO: uma narrativa a favor da democracia}

Esta etapa do trabalho pretende considerar dois aspectos referentes ao projeto político-pedagógico: o primeiro se destina a recuperar o quantitativo de produções acadêmicas realizadas por meio de teses e dissertações (acesso em 15 de março de 2016) na década de 2006/2015, numa comparação com seu último biênio 2014/2015, que resulta em ponderar a respeito da atualidade do tema, demonstrando o constante envolvimento dos pesquisadores. O outro aspecto o qual evidenciaremos é uma fundamentação teórica sobre o assunto e um diálogo a partir da prática vivenciada junto a rede municipal de educação de uma cidade da região metropolitana Vale do Paraíba, no estado de São Paulo.

Comecemos pela demonstração de teses e dissertações sobre o tema: projeto político-pedagógico, a partir dos dados disponibilizados pelo Instituto Brasileiro de Informação em Ciência e Tecnologia - IBICT, vinculado ao Ministério de Ciência e Tecnologia brasileiro, na década de 2006/2015, onde localizamos 611 dissertações e 216 teses, totalizando 827 trabalhos. Destes, encontramos no último biênio (2014-2015): 119 dissertações e 59 teses, que somam 178 produções (GRÁFICO 1).

GRÁFICO 1 - Quantitativos de trabalhos finais de Doutorados e Mestrados, referentes ao descritor - Projeto Político-Pedagógico. Brasil - 2006/2013 e seu último biênio 2014/2015.

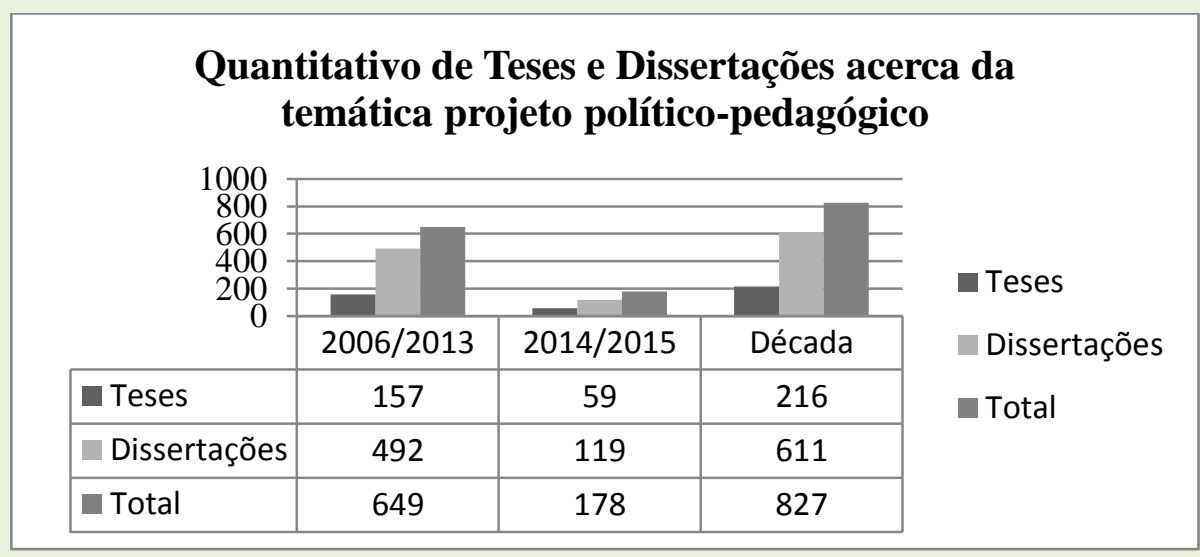

FONTE: A autora 
Se compararmos o biênio 2014/2015 com a década 2006/2015, veremos uma produção recente que representa $21,52 \%$ do total, ou seja, dos 827 trabalhos atingidos na década, cento e setenta e oito foram no seu último biênio. Isto significa que o tema não vem perdendo relevância no tempo, pelo contrário, significa mais de um quinto da produção total da década.

Ademais, mesmo que possamos dizer que o último biênio representou praticamente um quinto da produção de sua década, ao compararmos com a produção de teses, vemos um incremento significativo, o que por outro lado demonstra o reconhecimento de estudos com maior temporalidade sobre a temática, o que sem dúvida propicia maiores reflexões e aprofundamentos. Teses no biênio alcançaram $27 \%$ do total da produção decenal, o que indica um possível fôlego a respeito da importância da temática, mesmo tanto tempo depois da promulgação da LDB (BRASIL, 1996).

GRÁFICO 2 - Quantitativos de trabalhos finais de Doutorado, referentes ao descritor - Projeto Político-Pedagógico. Brasil - 2006/2013 e o biênio 2014/2015.

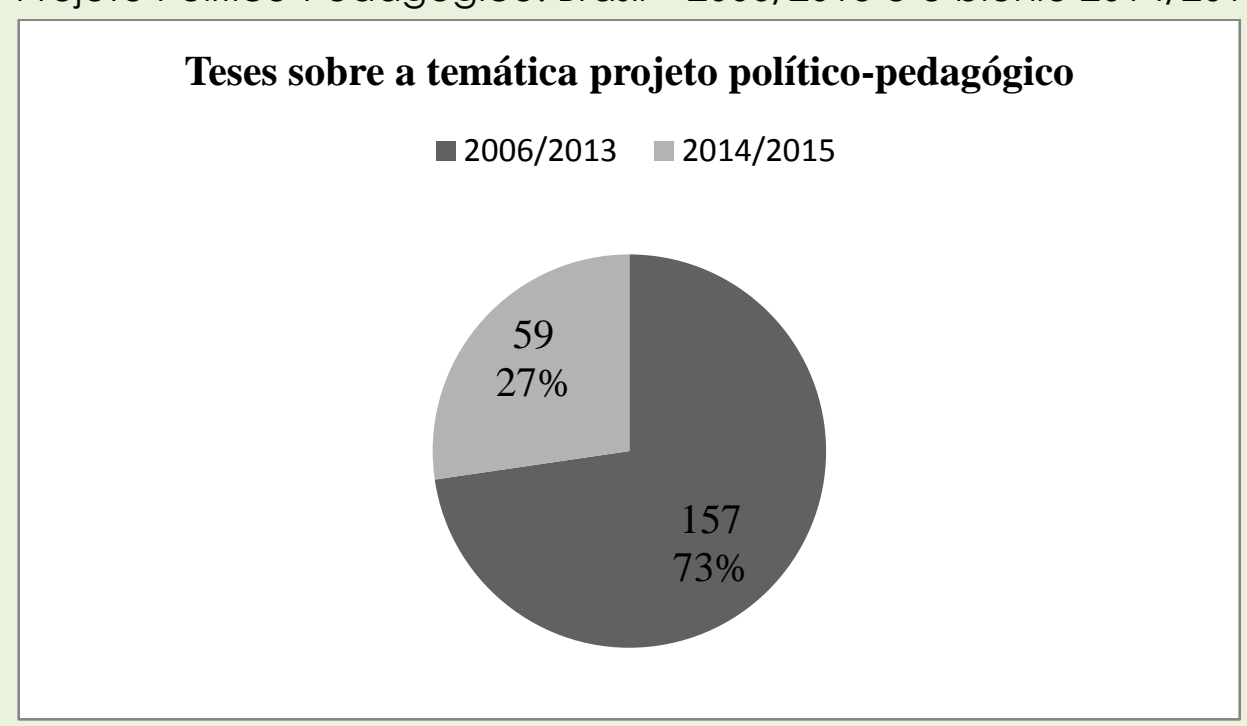

FONTE: A autora

O que estamos considerando é que mesmo diante de uma prerrogativa legal, de que os PPP fossem realizados, podemos compreender que importantes trabalhos acerca dos estudos em educação sobre a temática dimensionam a seriedade deste instrumento no cotidiano 
educacional, o que pode significar que há um desejo de que a educação se faça enquanto um projeto, e não ao contrário, que o projeto se faça enquanto uma obrigação legal.

Verificamos que os trabalhos acadêmicos dialogam com diversas modalidades do ensino e temas, como por exemplo, a questão da escola do campo, grupos étnicos, direito das crianças, gestão, formação de professores, currículo, disciplinas; tanto na universidade, quanto na educação básica. O que deflagra que em todos os diversos componentes de análise, é no projeto político-pedagógico da instituição que o pesquisador busca as reflexões necessárias para o entendimento do seu objeto de estudo.

E essa riqueza de diversidade sobre os elementos que se articulam ao PPP parece-nos estar demonstrando uma sintonia de que é - o Projeto Político-Pedagógico - um instrumento que articula propostas e políticas no estabelecimento escolar. E é, por meio deste dispositivo, que as pesquisas vêm se debruçando e dando amplitude ao objeto em análise.

Sendo assim, na intenção de articularmos a construção de PPPs à premissa analisada anteriormente, sobre a democracia participativa, compreendemos que as contradições frente ao estado de coisas que encontramos em nosso cotidiano, que deflagram um mundo de violências, consumismos e individualismos, pretendem colaborar para análise a partir do compromisso da escola com outro projeto de sociedade, baseada na construção plural e coletiva.

Diante disso, perguntamo-nos sobre as condições da escola em se apropriar da conjuntura instalada e ajudar a construir novos parâmetros contra hegemônicos. Não como se fosse capaz de mudar o curso da história, sozinha, mas como uma instituição importante na promoção do empenho humanitário, no sentido de contribuir para uma vida com mais qualidade e dignidade.

Perspectivados sobre este pensamento, compreendemos que a delimitação de nosso construto acerca da democracia é a reflexão sobre a 
construção necessária para promover o bem viver, marcados pelos elementos de igualdade e justiça. Reforçamos, por isso, a importância de numa gestão escolar que promova, dialogicamente, tais ponderações.

Daí, recuperamos a relevante análise trazida por Wallerstein (2003), a qual denota ser preciso criar alternativas viáveis para a superação da realidade vivida, por meio de uma avaliação da situação em que nos encontramos. Esta, sem dúvida é uma tarefa necessária para os projetos políticos pedagógicos das instituições educativas, que se queiram comprometidos com as mudanças sociais, históricas e culturais.

Neste sentido, trazemos a ideia das utopias, as quais alimentam em última instância, os desejos por dias melhores. Ao contrário dos discursos que reforçam que as utopias forjam a desesperança, porque vêm ancoradas em promessas que quase nunca se realizam. É preciso, por isso, ter clareza histórica, do limite das possibilidades e da existência do processo contraditório. Desse modo, encontramos em Gramsci (COUTINHO, 2004) uma importante consideração, a qual elucida o que estamos dizendo:

A Revolução Francesa abateu muitos privilégios, ergueu muitos oprimidos, mas não fez mais do que substituir a dominação de uma classe pela outra. Deixou, porém, uma grande lição: que os privilégios e as diferenças sociais, sendo produtos da sociedade e não da natureza, podem ser superados (p. 46).

O fato, portanto, de privilégios, desigualdades sociais entre tantos outros produtos criados por nossa construção histórica, demonstra a possibilidade de serem reinventados, porque somos sujeitos históricos, sociais e políticos. Isto posto, consideramos que os projetos políticos-pedagógicos podem sim guardar os melhores desejosos de uma sociedade mais igual, e a partir dele a escola se comprometer com outro mundo mais bonito.

De tal modo, ponderamos que o termo político, o qual adjetiva o projeto da escola, apresenta a possibilidade de uma construção democrática. Isto porque, a política enquanto "produção de convivência entre as pessoas e grupos" (PARO, 2010) pode ocorrer de duas formas: pela 
dominação ou pelo diálogo democrático. As pessoas envolvidas no processo educativo, na qualidade de sujeitos históricos, sociais e políticos, têm, por isso, uma inquietante escolha, e uma instigante tarefa, a serem realizadas.

O exercício desenvolvido até aqui se dá na direção de que o compromisso histórico reiterado por Wallerstein (2003), considerado por Gramsci (COUTINHO, 2004) e renovado por Paro (2010) se sustentará no processo democrático. E nesta perspectiva a escola que tem em seu PPP, seu projeto de sociedade, buscará nos processos democráticos sua elaboração e posterior execução.

Balizados por este arcabouço teórico-reflexivo, passamos a tecer uma articulação à luz da experiência realizada por uma Secretaria Municipal de Educação (SME), junto à sua Diretoria Técnica Pedagógica (DTP - a qual é responsável pela promoção das políticas pedagógicas da rede municipal de educação), numa cidade da região metropolitana do Vale do Paraíba/SP. Assim, realizaremos um diálogo entre projeto políticopedagógico a partir dos conceitos analisados e o campo empírico e viceversa.

No ano de 2013, tal diretoria fez seu planejamento e em seu objetivo geral estava disposto à vontade de contribuir para que a escola se fizesse numa perspectiva democrática:

\footnotetext{
Promover uma rede educacional, enquanto equipamento social (espaço físico, organização e ações) que priorize a participação e a valorização de todos os envolvidos no processo educativo, viabilizando a construção do conhecimento, a formação integral do sujeito e a cidadania, favorecendo a justiça social (JACAREí, Planejamento da Diretoria Técnico Pedagógica, 2013).
}

Dito isso, evidenciamos o desejo de uma esfera da instituição educativa. Porém, para afirmarmos um processo democrático, é preciso que as pessoas envolvidas no cotidiano escolar possam ser escutadas. Afinal, não há nada mais antidemocrático que uma secretaria de educação, ou 
qualquer órgão que valha ao "topo da hierarquia", prescrever o que deve ser feito no chão da educação - a escola propriamente dita.

Como já referimos anteriormente, ancorados em Bobbio (1986): o processo democrático está em permanente construção, e ao nosso entender isso significa que não se realiza por um nível da hierarquia burocrática educacional, mas ao contrário, se efetiva na co-autoria participativa do conjunto de envolvidos. Assim, ao mesmo tempo que não está dada, a democracia não pode ser querida numa única esfera da organização educacional pública, sem estar sendo buscada na outra. Ou seja, não há como uma SME promover meios para que a escola se faça democrática, se ela mesma não se fizer.

Aliás, aferimos que o histórico de participação das escolas na organização das políticas educacionais geralmente não são uma prática recorrente. Pelo contrário, a forma de poder exercida por boa parte das estruturas hierárquicas da organização educacional são caracterizadas, por um lado, por uma forte centralização e, por outro, pela obediência das esferas subordinadas. Não é à toa que as escolas têm na figura do diretor uma forte presença de mando e autoritarismo, pois isso é o reflexo da concepção da organizativa do arcabouço educacional. Então, ao reforçamos a ideia de que uma sociedade democrática é aquela que se apropria do direito de participar do poder político e social e constrói efetivamente um Estado do qual ela se sente parte, reforçamos também que uma organização educacional, responsável pela constituição de políticas educacionais deva primar por uma construção de políticas de forma democrática.

Retomando a ideia apresentada por Bobbio (1986) que só haverá aumento da democracia quando todos exercerem seu poder de cidadãos e cidadãs por meio da participação e do controle popular, pode-se concluir que o Estado e suas instâncias só poderão ser efetivamente democráticos, quanto mais a sociedade democrática o empurrar para este devir. Sendo assim, parece elementar que a democracia só será exercida pela 
organização educacional, se a comunidade educativa (pais, professores, equipes gestoras, alunos, funcionários, técnicos da SME etc) exercerem sua cidadania na construção das políticas educacionais.

Veiga (2003) sugere que as mudanças ocorrem a partir das partes para o todo. Obviamente não há como mudar o todo, sem haver modificações nas partes. E essas não mudam igualmente. Por isso, a democracia exige um estar permanente alerta, refletindo sobre o que está acontecendo, comparando com o desejado, revisitando seus princípios e suas práticas, o que se está fazendo e atingindo. Ou seja, realizando uma constante avaliação das rotas, do percurso conseguido.

Diante disso, podemos propor que de acordo com o planejamento da DTP havia um desejo de que se fizesse democraticamente, para que a organização escolar assim se constituísse.

De posse desse sentimento, foi proposto um diálogo com representação das escolas municipais, no sentido de haver a construção coletiva dos PPPs até dezembro de 2014 como um documento "vivo" que norteasse e promovesse a identidade de cada escola, seus objetivos e sua finalidade.

Porém, antes de descrevermos o processo instaurado junto à rede municipal, queremos enfatizar uma das discussões mais importantes realizadas pelos membros dessa diretoria, em torno da polêmica acalorada, quando da seguinte situação: se o que havia sido instituído na rede até aquele momento, com o nome de "planos escolares" era a mesma coisa que projetos político-pedagógicos.

Quando do planejamento da DTP, foram criados seis grupos de estudos: educação integral; brincagem (na perspectiva de uma articulação entre ensino-aprendizagem e brincar); currículo e avaliação; formação e assessoria; gestão democrática; projeto político-pedagógico e regimento. Então, nesse momento, o grupo de estudos sobre PPP interveio, firmando sua posição diante da indagação, de que os planos escolares compreendiam uma formulação mais técnica (VEIGA, 2003) - (e menos política) e nada 
participativa e democrática. Pelo contrário, na grande maioria das vezes havia por parte do diretor escolar a feitura propriamente dita dos planos escolares, e quando havia a participação dos professores, por exemplo, era somente para colocar seus projetos em anexo, ou seja, o trabalho que desenvolveriam em "sua sala de aula".

Isso sem considerar a reflexão proposta anteriormente, de que os demais atores do processo educacional, têm tanto direito quanto necessidade de participarem. Ou ainda, a ideia tão reforçada no diálogo recém-abordado, de que o projeto, assim como seu significado indica, é uma proposta de direção, de concepções, de delineamento do que a escola quer ser. Por conseguinte, os planos escolares, existentes nas escolas desta rede municipal, não configuravam projetos de escola, porque evidentemente, não guardavam seus principais elementos políticos, quais eram: de promover a participação de todos os atores da comunidade escolar em sua elaboração; de ser um instrumento de debate e diálogo daquilo que definiria os destinos da própria escola e seu sentido.

O processo de construção do projeto político-pedagógico pode
contribuir, portanto, para a constituição das identidades dos sujeitos
nas dimensões sociais, éticas e políticas, em uma perspectiva crítica.
Obviamente, isso pressupõe uma percepção desse projeto como um
instrumento de organização dos sujeitos sociais no interior da
instituição escolar e não como um documento meramente
burocrático, encomendado a terceiros. Essa tarefa é complexa
porque, ao mesmo tempo em que a escola deve buscar a
convergência e a consciência dos interesses dos sujeitos envolvidos
na organização de todo o trabalho pedagógico, precisa estimular a
participação dos grupos em seu interior, respeitando suas
especificidades (SOUZA, 2001, p. 235).

A partir daí, todos os membros da DTP passaram a estudar sobre projeto político-pedagógico, para que efetivamente pudessem contribuir para uma articulação democrática com as escolas. Isso, porque são os componentes dessa diretoria que prestam assessoria e supervisão diretamente às escolas. Nesse sentido, sua compreensão, seu envolvimento, sua presença são fundamentais para qualquer mudança a ser pretendida na concepção de educação municipal, no sentido da organização de um 
trabalho em rede como foi pretendido. A proposta não era de uma escola, mas sim para todas as escolas mantidas pelo poder público do município.

Um dos textos que embasaram a construção dos PPPs na rede, foi o dos autores Gandin e Gandin (2011) os quais fazem uma análise de três diferentes tendências de planejamento: o planejamento participativo, o planejamento estratégico e o gerenciamento da qualidade total. Sobre esses, chegam a seguinte definição:

Completando o item anterior e buscando ver qual a atenção especial de cada uma das tendências, destaco: as ferramentas que gravitam ao redor do gerenciamento da qualidade total assumem com força a ideia de que a finalidade do planejamento é satisfazer - cliente; para o planejamento estratégico (alguns preferem "Administração Estratégica") o propósito último é firmar-se no mercado, melhor, produzir ambiente de lucro futuro e, portanto, de permanência; o planejamento participativo quer contribuir para a transformação da sociedade na linha da justiça social, no sentido de que todos participem das decisões, mas sobretudo dos bens materiais e não materiais encontrados na natureza ou produzidos pelas pessoas humanas (GANDIN, GANDIN, 2011, p. 44) [grifos do autor].

Sendo assim, a concepção de projeto político-pedagógico que passou a ser assumida contou com a colaboração de diversos artigos estudados sob a coordenação do grupo de estudos e palestras com a DTP e representantes das escolas municipais (equipes gestoras, professores e funcionários) com os professores Vitor Paro, Júlio Furtado, Andrea Fetzner, Cláudia Fernandes e Maria Elena Viana Souza, os quais eram convidados a fazerem uma articulação entre os temas PPP e currículo.

Uma síntese possível, assim se expressa:

O Projeto Político Pedagógico é a identidade, é a "Constituição" da escola. Ele é político porque é um compromisso social, já que se compromete com a formação do cidadão para um tipo de sociedade que se deseja e é Pedagógico porque define as ações educativas e as características necessárias à escola para que ela cumpra seu propósito. Um PPP deve contemplar a missão da escola (ou marco referencial), que é a declaração explícita dos valores e aspirações da escola. A missão deve responder principalmente a 
duas perguntas: em que educação essa escola acredita? e que aluno queremos formar? (FURTADO, 2014) 103.

E foi dessa maneira que a DTP passou a dialogar com uma representação de todas as unidades escolares, por meio da seguinte proposta: por volta de duzentas pessoas passaram a participar de encontros com a DTP sobre a temática exposta. E contando com os professores mediadores convidados e expostos acima, traziam as discussões realizadas nas escolas sobre o que era construir um documento político-pedagógico, que significasse um projeto identitário da escola - o que deveria ser incorporado, como fazer um documento com a participação dos envolvidos e para quê.

A partir daí, acontecia uma avaliação dos diversos artigos, livros, documentários, entrevistas analisados pelo grupo de estudos os quais eram compartilhados com a DTP e com as escolas, no sentido de buscarem embasamento teórico para o momento que experimentavam - de uma construção de que escola estavam propondo e para quê.

Diante disso, houve a solicitação de muitas escolas, que reivindicavam tempo para que um documento nesse teor fosse organizado, foram propostos, para o calendário escolar, e materializados, os Planos Pedagógicos. Ou seja, todas as escolas, de todas as modalidades de ensino, passaram a ter em torno de oito encontros anuais para que todos os profissionais fossem envolvidos no processo coletivo de organização dos seus PPPs, incluindo toda comunidade escolar. Assim, nesses dias, as discussões se dariam para construir o documento.

Obviamente a organização dos PPPs foi muito distinta entre as unidades escolares da rede municipal, porém, pudemos perceber o movimento intenso entre todas elas. Algumas escolas conseguiram avançar mais na participação, outras nem tanto, porém, o movimento de que é de cada realidade, inserida na sua comunidade estava resguardado. E a rede

103 Disponível em: http://juliofurtado.com.br/projeto-politico-pedagogico-curriculo-e-gestaodemocratica-algumas-perguntas-e-respostas/). 
como um todo, passou a viver as possibilidades de uma democracia participativa.

\section{4 À GUISA DE CONCLUSÃO}

Como propõem Shor e Freire (1986), ao se perguntarem a respeito da aprendizagem na dimensão do empoderamento, construíram o entendimento de que não basta ao final do ano letivo os alunos se sentirem mais críticos, com melhor compreensão do mundo se isto não gerar mudanças e qualidade de vida para todos. Se homens e mulheres são seres de interdependência, unos e diversos, o empoderamento também não poderá acontecer somente enquanto indivíduo, isolado um do outro, mas, ao contrário, só se dará se um se comprometer com a luta do outro, coletivamente. Assim, um PPP torna-se efetivamente possível se encarar os desafios de constituir-se como um projeto de escola, inserido em sua realidade, com objetivos compreensíveis, os quais tornem factível um pensar sobre si, sobre suas questões, sobre seu sentido - sua inserção no mundo; incentivador e potencializador de uma construção verdadeiramente coletiva.

É necessário, portanto, que o empoderamento se efetive não apenas individualmente, mas de forma a promover um bem comum, uma vida melhor para todos. Portando, o PPP pode ser um instrumento de elaboração a favor das transformações sociais.

Empoderamento, democracia e participação acontecem no propósito de realizar oportunidades de uma vida mais igual para todos; e a construção desses processos democráticos torna o Projeto Político Pedagógico, de fato, um plano realizável.

$\mathrm{Na}$ democracia as pessoas se afirmam como sujeitos (PARO, 2010). Assim, a escola, como instituição que tem por fim contribuir para a formação de cidadãos, terá como tarefa primordial, investir em seu próprio protagonismo. 
Diante disso, o presente trabalho levou em conta a construção de PPPs garantindo a cada unidade escolar, a reflexão sobre seu projeto de educação. Obviamente, isso não se faz magicamente, nem no sentido de grandes mudanças, muito menos no sentido de modelos a serem "copiados". Pelo contrário, os processos são lentos. Necessitam de rupturas com os padrões estabelecidos, na direção de um aprendizado possível de transformações do cotidiano, o qual, até aqui, estava centralizado e determinado pela hierarquia educacional.

\section{REFERÊNCIAS}

BENEVIDES, M. V. de M. A cidadania ativa: referendo, plebiscito e iniciativa popular. $2^{a}$ ed. São Paulo: Editora Ática, 1996.

BOBBIO, N. O futuro da democracia: uma defesa das regras do jogo. Rio de Janeiro: paz e Terra, 1986.

BORON, A. A. Os "novos Leviatãs" e a polis democrática: neoliberalismo, decomposição estatal e decadência da democracia na América latina. In: SADER, Emir; GENTILI, Pablo (orgs). Pós-neoliberalismo Il: que Estado para que democracia? $5^{\mathrm{a}}$ ed. Petrópolis, RJ: Vozes, 2009.

BRASIL. Constituição Federal (1988). Constituição da República Federativa do Brasil. Brasília, DF: Senado Federal, 1988.

BRASIL. Lei n. 9394, de 20 de dezembro de 1996. Lei de Diretrizes e Bases da Educação Nacional. Brasília, 1996.

BRASIL. Lei $n^{\circ}$ 13.005, de 25 de junho de 2014. Aprova o Plano Nacional de Educação - PNE e dá outras providências. Brasília, 2014.

COUTINHO, C. N. (org.). GRAMSCl, A. Escritos políticos. Rio de Janeiro: Civilização Brasileira, 2004.

GADOTTI, M. Projeto político-pedagógico da escola: fundamentos para sua realização. IN: GADOTTI, M.; ROMÃO, J. E. (orgs). Autonomia da escola: princípios e propostas. $7^{a}$ ed. São Paulo: Cortez, 2012.

GANDIN, D.; GANDIN, L. A. Temas para um Projeto Político-Pedagógico. $12^{a}$ ed. Petrópolis, RJ: Editora Vozes, 2011.

GREEN, D. Da pobreza ao poder: como cidadãos ativos e Estados efetivos podem mudar o mundo. São Paulo: Cortez, Oxford: Oxfam International, 2009.

HOBSBAWN, E. Globalização, democracia e terrorismo. São Paulo: Companhia das Letras, 2007. 
JACAREÍ. Planejamento da Diretoria Técnico-Pedagógica. 2013.

MAINARDES, J. Abordagem do ciclo de Políticas: uma contribuição para a análise de políticas educacionais. Educação e Sociedade, Campinas, vol 27, $n^{\circ}$ 94, jan./abr. 2006.

PARO, V. H. Gestão Democrática da Escola Pública. $3^{a}$ ed. São Paulo: Ática, 2000.

PARO, $\mathrm{V}$ H. Educação como exercício do poder: crítica ao senso comum em educação. $2^{a}$ ed. São Paulo: Cortez, 2010. (Questões de nossa época, v. 4).

SHOR, I.; FREIRE, P. Medo e Ousadia: o cotidiano do professor. Rio de Janeiro: Paz e Terra. 1986.

SOUZA. J. V. de. A identidade do sujeito social, ético e político do projeto pedagógico da escola. IN: VEIGA, I. P. A.; FONSECA, M. (orgs). As dimensões do projeto político-pedagógico: Novos desafios para a escola. $9^{a}$ ed. Campinas, SP: Papirus, 2001. p. 215 - 237. (Coleção Magistério: formação e trabalho pedagógico).

TOURAINE, A. O que é a democracia? 2a ed. Petrópolis, RJ: Vozes, 1996.

VEIGA, I. P. A. Inovações e projeto político-pedagógico: uma relação regulatória ou emancipatória? Cad. Cedes, Campinas, v. 23, n. 61, p. 267281, dezembro 2003. Disponível em <http://www.cedes.unicamp.br>.

VIOLA, E. S. A. Direitos humanos e democracia no Brasil. São Leopoldo/RS: Editora Unisinos. 2008.

WALLERSTEIN, I. Utopística, ou, As decisões históricas do século vinte e um. Petrópolis, RJ: Vozes, 2003.

\section{Sites consultados:}

http://juliofurtado.com.br/projeto-politico-pedagogico-curriculo-e-gestaodemocratica-algumas-perguntas-e-respostas/ Acesso em 07 de abril de 2016. http://www.cedes.unicamp.br Acesso em 27 de abril de 2016.

http://bdtd.ibict.br/vufind/Search/Results?lookfor=projeto+pol\%C3\%ADticopedag\%C3\%B3gico\&type=AllFields Acesso em 15 de março de 2016.

Recebido em: Maio de 2016

Aceito em: Outubro de 2016 